\title{
Experimental Coxiella burnetii infection in non-pregnant goats and the effect of breeding
}

Hendrik I. J. Roest ${ }^{1,5^{*}} \mathbb{D}$, Annemieke Dinkla' ${ }^{1}$ Ad P. Koets ${ }^{1,2}$, Jacob Post ${ }^{3}$ and Lucien van Keulen ${ }^{4}$

\begin{abstract}
Q fever is a zoonosis caused by the intracellular bacterium Coxiella burnetii. In Europe, small ruminants are the main source of human Q fever. Small ruminant herds can be infectious during several lambing seasons. However, it is not clear how infection is maintained in a herd and what role non-pregnant animals play in the transmission of C. burnetii. We therefore inoculated nulliparous goats with C. burnetii, isolated from the outbreak of Q fever in the Netherlands, to gain a better understanding of the role of non-pregnant goats. Seroconversion and excretion of C. burnetii were monitored after inoculation. To study the effect of breeding on the excretion of C. burnetii, the goats were naturally bred and monitored during gestation and after lambing. Our results indicate that $C$. burnetii infection prior to breeding did not result in infection of the placenta nor did it affect the gestation length or the number of kids born. However, one of the ten does did excrete C. burnetii in the colostrum post-partum and the bacterium was detected in the mammary gland and associated lymph nodes at necropsy. This result indicates that non-pregnant goats might play a role in maintaining $\mathrm{Q}$ fever in a goat herd as persistent carriers of infection.
\end{abstract}

\section{Introduction}

$\mathrm{Q}$ fever is a zoonosis caused by the intracellular bacterium Coxiella burnetii. The zoonotic impact of the disease has been shown in various outbreaks [1-3]. The Dutch Q fever epidemic was the biggest outbreak reported so far, with 4029 registered human cases during the years 2007-2010 and more than 40000 people assumed to be infected following (bio-aerosol) exposure $[2,4]$. Upon infection, clinical symptoms in humans vary from no symptoms at all to a flu-like, self-limiting disease, atypical pneumonia or hepatitis in the acute phase. In the chronic forms humans may suffer from a life-threatening endocarditis or chronic fatigue. Currently 439 chronic Dutch $\mathrm{Q}$ fever patients are registered [5].

\footnotetext{
*Correspondence: h.i.j.roest@min|nv.nl

${ }^{5}$ Present Address: Ministry of Agriculture, Nature and Food Quality, The Hague, The Netherlands

Full list of author information is available at the end of the article
}

In Europe, small ruminants are the main source of infection for human $Q$ fever [6]. They excrete high amounts of $C$. burnetii during abortion or premature and end-term parturition of infected does. Humans become infected via direct or indirect contact with contaminated aerosolized birth material. In large goats herds, abortion rates can reach up to $80 \%$ of the infected pregnant animals although healthy kids can also be born $[2,6,7]$.

It is not quite clear how $Q$ fever persists in sheep or goat herds. Publications describe Q fever outbreaks in goat herds and excretion of $C$. burnetii during successive parturitions of the same animal [8-11]. However, these case studies do not clarify how pregnant does become reinfected. There are three possible scenarios. Firstly, placentas can be infected with C. burnetii that persist in the genital tract after an infected parturition as found by Alsaleh et al. [12]. Secondly their placental tissue can become reinfected from bacteria persisting elsewhere in the goat's organs during the interpregnant period, for instance in the mammary tissue [13]. Thirdly, animals can

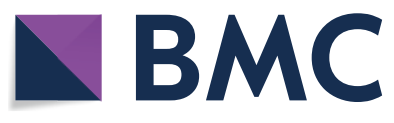

(c) The Author(s) 2020. This article is licensed under a Creative Commons Attribution 4.0 International License, which permits use, sharing, adaptation, distribution and reproduction in any medium or format, as long as you give appropriate credit to the original author(s) and the source, provide a link to the Creative Commons licence, and indicate if changes were made. The images or other third party material in this article are included in the article's Creative Commons licence, unless indicated otherwise in a credit line to the material. If material is not included in the article's Creative Commons licence and your intended use is not permitted by statutory regulation or exceeds the permitted use, you will need to obtain permission directly from the copyright holder. To view a copy of this licence, visit http://creativeco mmons.org/licenses/by/4.0/. The Creative Commons Public Domain Dedication waiver (http://creativecommons.org/publicdomain/ zero/1.0/) applies to the data made available in this article, unless otherwise stated in a credit line to the data. 
be reinfected from a contaminated environment despite humoral and cellular immunity.

Experimental infections in pregnant goats, however, could not confirm the persistence of $C$. burnetii in mammary glands $[7,14,15]$. Moreover, excretion in the milk was found to be limited to 32 days post-partum [7]. Overall, field data and data from experimental infections are contradictory and do not explain how a C. burnetii infection is maintained in a herd.

Non-pregnant goats might play a role in maintaining $\mathrm{Q}$ fever in a herd. However, it is impossible to assess their role in a field case study as environmental infection conditions are not controlled and no diagnostic methods are known to assess the actual infection moment or the possible persistence of $C$. burnetii in live animals. An experimental infection is needed to elucidate the role of non-pregnant goats. Therefore, the goal of this study was to assess $C$. burnetii infection and (milk) excretion in non-pregnant nulliparous goats up to the outcome of the first pregnancy and start of lactation. In this experiment, successful inoculation was evaluated by the detection of serum antibodies and excretion was monitored via vaginal swabs, feces, colostrum and air samples. Goats were synchronized and bred, and after parturition, placenta's, kids, mammary glands, and colostrum were investigated by C. burnetii-specific PCR. None of the inoculated goats excreted C. burnetii during parturition. One of the goats, however, excreted $C$. burnetii in the colostrum and C. burnetii DNA was detectable in the mammary gland and the associated lymph node.

\section{Materials and methods Inoculum}

Coxiella burnetii strain X09003262-001 was used as previously described [7]. In summary, the strain is a representative of the Dutch C. burnetii outbreak strain, isolated from the placenta of a goat which aborted due to $\mathrm{Q}$ fever [17]. The strain was isolated using a Buffalo Green Monkey (BGM) cell culture. The mouse-infective dose (MID) was determined and prior to inoculation, the inoculum was adjusted to the required MID by dilution with culture medium. Cell culture passage 2 of the field isolate was used to ensure inoculation of phase 1 bacteria. In the inoculum, no phase 2 C. burnetii were detected with an immunofluorescence test that was set up with the serum of a goat with a high anti-phase 2 antibody titer but without phase 1 antibodies. The animal trail was conducted in accordance with the Dutch Law on Animal Experimentations (Wet op de Dierproeven, ID number 2013037c) and the European regulations on the protection of animals used for scientific purposes (EU directive 2010/63/EU).

\section{Animal experiment Animals and inoculation}

Twenty-four healthy, serologically $Q$ fever negative, Alpine goats were purchased from INRAE (Institut national de recherche pour l'agriculture, l'alimentation et l'environnement, Domaine de Galle), France. Upon arrival the non-pregnant nulliparous goats were 15 weeks old and tested serological negative for antibodies against C. burnetii (LSIVET RUMINANT milk/serum Q-fever ELISA kit, LSI, Lyon, France) and Chlamydia abortus (Chekit Chlamydophila abortus antibody test kit, IDEXX laboratories B.V., Hoofddorp, the Netherlands). After 1 week of acclimatization, 16 goats were divided over two animal rooms in the animal biosafety level 3 (aBSL3) facility. Goats were intranasally inoculated with $1 \mathrm{~mL}$ containing $10^{6}$ MID C. burnetii with a nozzle in the left nostril with the right nostril closed during forced inhalation. Eight negative control animals remained outside the aBSL3 facilities and were intranasally inoculated with $1 \mathrm{~mL}$ of culture medium. This inoculation procedure was used previously to inoculate pregnant goats. This resulted in a successful infection with $C$. burnetii resulting in pathology, excretion of C. burnetii and abortion [7].

At 49 days post-inoculation (dpi), after repeated negative testing of individual blood and fecal samples and air samples for C. burnetii DNA, all C. burnetii inoculated animals were moved from aBSL3 to two animal rooms in the aBSL2 facility for estrus synchronization and breeding. The eight control animals remained in their initial aBSL2 animal room and underwent the same synchronization and breeding procedures as the $C$. burnetii inoculated animals (Table 1).

Goats had ad libitum access to water and hay and were fed limited amounts of concentrate on a once daily basis. The animals were group housed in aBSL2 and aBSL3 compartments with regulated temperature and humidity, with a 12/12 h light/dark cycle unless stated differently, in accordance with EU directive 2010/63/EU.

\section{Estrus synchronization and breeding}

From 91 dpi onwards, light was restricted to 11.5 hour (h) per day and reduced every week with half an hour till $10 \mathrm{~h}$ a day at $112 \mathrm{dpi}$ (Table 1) to mimic the shortening of day length during the change of season. At $115 \mathrm{dpi}$, a Progesterone vaginal sponge (Chronogest CR, MSD-Animal Health, Boxmeer, the Netherlands) was inserted and at $124 \mathrm{dpi} 0.2 \mathrm{~mL}$ Estrumate (MSD-Animal Health) and $1.25 \mathrm{~mL}$ Folligonan (MSD-Animal Health) were injected intramuscularly. On 126 dpi the sponge was removed and on 127 dpi all goats were naturally mated by a serologically $\mathrm{Q}$ fever negative tested buck that had not mated before. One goat was mated again 3 weeks later when she 


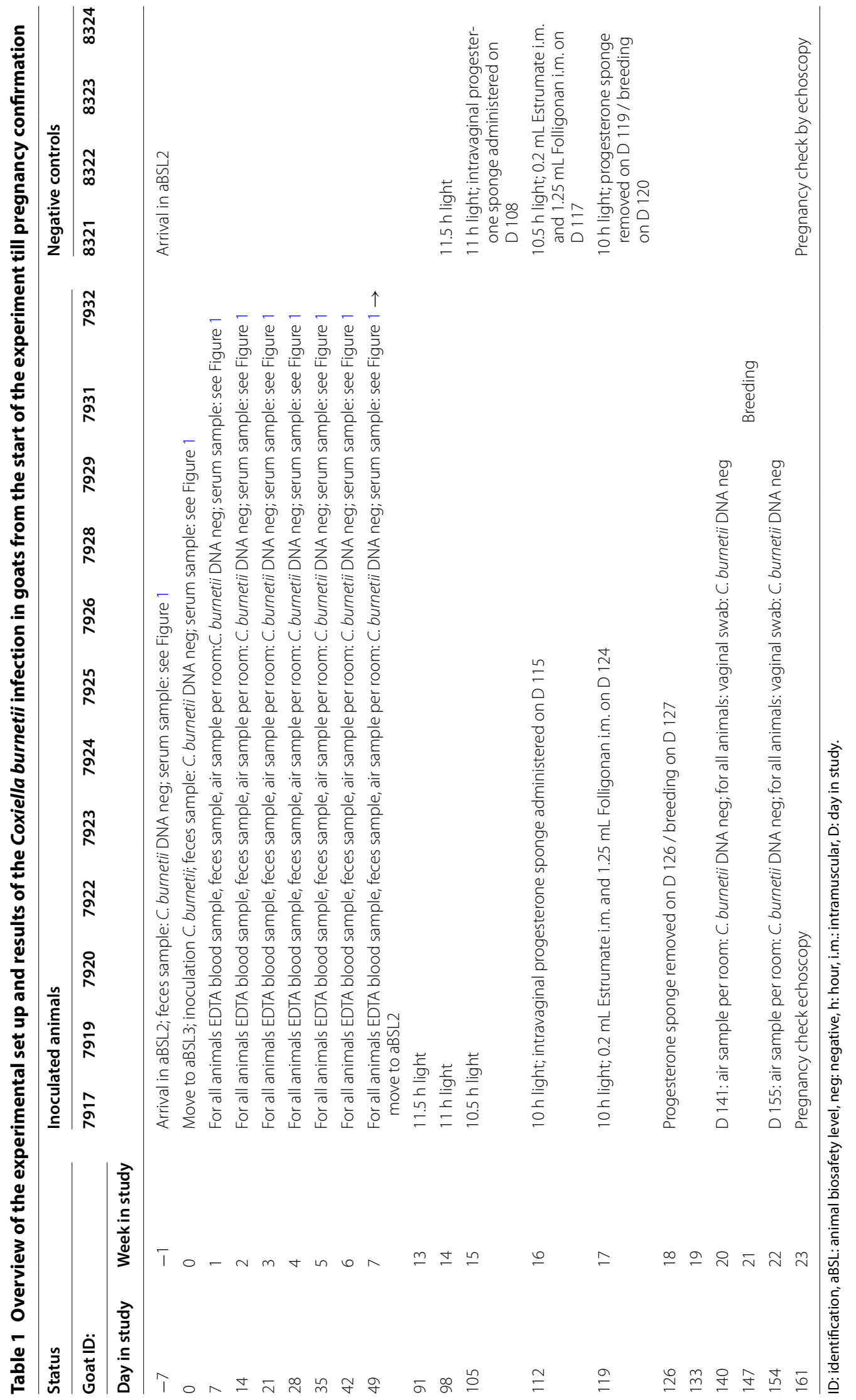


came into estrus again. On 161 and $168 \mathrm{dpi}$, gestation was checked by ultrasound scanning. Twelve C. burnetii infected goats and 4 control animals that were positively scanned for gestation were then moved to two boxes in aBSL3 facilities where they stayed until parturition (6 C. burnetii infected mixed with 2 control animals in each box, Table 2). In this step the control animals became sentinel animals. General health was monitored by daily clinical inspection of behavior, appetite, and consistency of the feces.

\section{Sampling}

At -7 dpi till 49 dpi jugular blood and rectal feces were sampled weekly from each $C$. burnetii inoculated goat. The air was sampled using an air sampler (MD 8 airscan Air Sampler Sartorius, Goettingen, Germany), as described previously [7]. After breeding and co-housing of infected and control animals, weekly blood samples were taken from the control animals to check for seroconversion (LSIVET RUMINANT milk/serum Q-fever ELISA kit, LSI). In addition, feces samples, vaginal swabs and air samples were taken around the expected parturition date (between 141 and 155 days of gestation, D268 and D282 of the experiment). Just after parturition, colostrum samples were taken from each goat from both teats.

\section{Necropsy}

Shortly after parturition, both does and kids were euthanized by intravenous injection of $50 \mathrm{mg} / \mathrm{kg}$ sodium pentobarbital (Euthasol ${ }^{\circledR}$, ASTfarma, Oudewater, the Netherlands) and subsequent exsanguination. At necropsy, the following tissues were sampled from the does: palatine tonsil, retro-pharyngeal lymph node, kidney, liver, spleen, lung, bronchial and mediastinal lymph nodes, mammary gland and the draining inguinal lymph node, iliacal lymph nodes, bone marrow, both ovaries, both oviducts, 3 caruncles from each uterus horn, noncaruncular mucosa from each uterus horn and colostrum. The following were sampled from each kid and afterbirth: spleen, liver, kidney, lung, umbilical cord, 3 cotyledons, 3 areas of non-cotyledonary allantochorion and blood.

\section{Serology}

In serum samples taken at -7 dpi till 49 dpi C. burnetii phase 1 and phase 2 IgM- and IgG-specific antibodies were detected in an ELISA format as described earlier [16]. In summary, C. burnetii phase 1 and phase 2 ELISAspecific plates were purchased from Virion/Serion (Serion ELISA classic Coxiella burnetii phase 1 and phase 2, Würzburg, Germany). Plates were incubated with 100 $\mu \mathrm{L}$ 1:160 diluted serum in phosphate buffered saline (PBS), pH 7.2 with $0.5 \mathrm{~mL} 10 \%(\mathrm{v} / \mathrm{v})$ tween 80 (PBS-Tw) for $1 \mathrm{~h}$ at $37{ }^{\circ} \mathrm{C}$. After incubation, plates were washed automatically (Schleicher, Dassel, Germany), 6 times with $1400 \mu \mathrm{L}$ of $0.5 \%$ Tween 20 in water and incubated for $1 \mathrm{~h}$ at $37^{\circ} \mathrm{C}$ with $100 \mu \mathrm{L}$ of diluted alkaline phosphatase-conjugated antibodies. For the detection of IgM antibodies, rabbit anti-goat IgM antibodies (Bioconnect, Huissen, the Netherlands) were used, 1:1000 diluted in PBS-Tw and $0.5 \mathrm{M} \mathrm{NaCl}$ for the detection of phase 1 antibodies or 1:5000 diluted for the detection of phase 2 antibodies. For the detection of IgG antibodies rabbit $\mathrm{F}(\mathrm{ab}) 2$ antigoat IgG (H/L) (Bioconnect) were used, 1:2000 diluted for the detection of phase 1 antibodies or 1:4000 diluted for the detection of phase 2 antibodies. After incubation with the conjugate, plates were washed as described above, $100 \mu \mathrm{L}$ of para-nitrophenylphosphate substrate

Table 2 Overview of the experimental set up and results of the Coxiella burnetii infection in goats during pregnancy

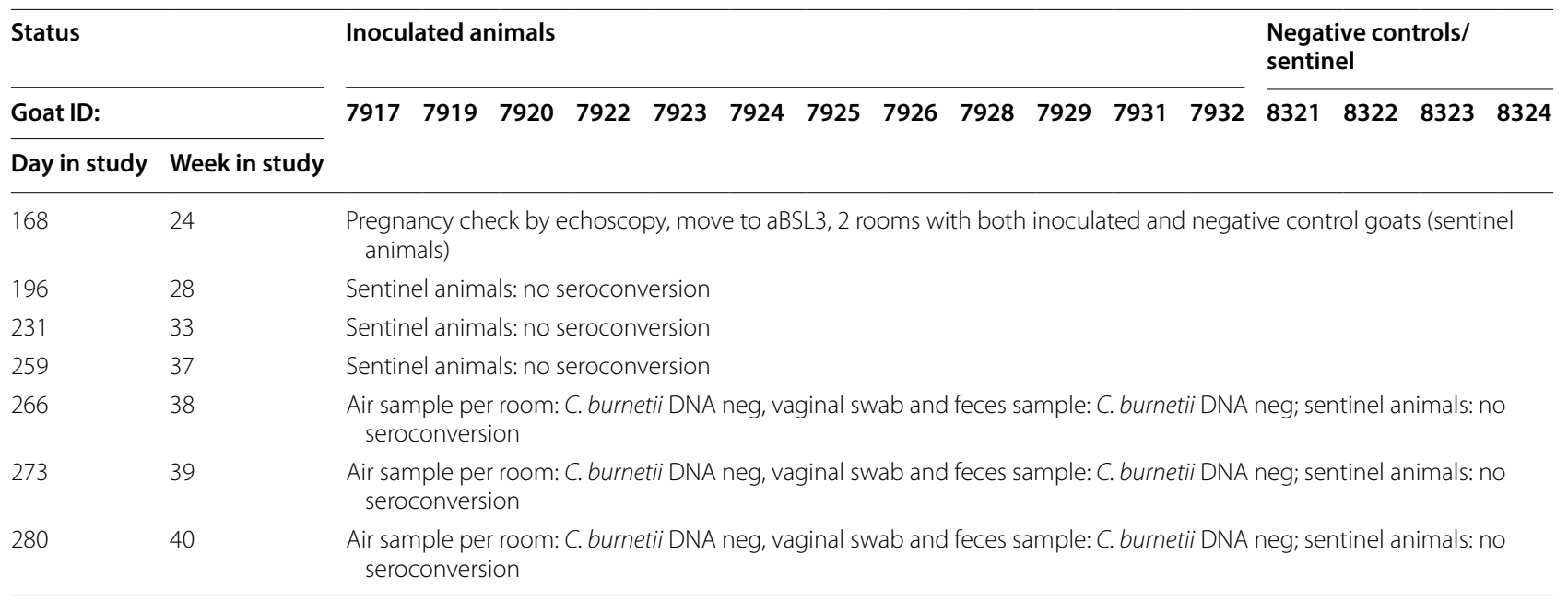

ID: identification, aBSL: animal biosafety level, neg: negative. 
(Virion/Serion) per well was added, and the reaction was stopped after $30 \mathrm{~min}$ at $37^{\circ} \mathrm{C}$ with $100 \mu \mathrm{L}$ of $1.2 \mathrm{~N}$ sodium hydroxide (Virion/Serion). The optical density (OD) was measured at $405 \mathrm{~nm}$ (EL 808 Ultra microplate reader, Bio-tek Instruments, Winooski, USA). On each plate the same negative and positive control serum was tested in duplicate per phase/Ig combination. Results of the serum were given related to the average positive control OD corrected for the average negative control OD. The average $C$. burnetii-specific antibody responses upon C. burnetii inoculation of 16 non-pregnant nulliparous goats were compared to the antibody response on $0 \mathrm{dpi}$.

\section{PCR for detection of Coxiella burnetii}

DNA was extracted from tissues $(20 \mathrm{mg})$, feces $(20 \mathrm{mg})$, vaginal mucus swabs (swab tip), EDTA blood $(200 \mu \mathrm{L})$, colostrum $(200 \mu \mathrm{L})$, and environmental samples (filter part the size of a swab tip) using a DNA tissue kit (DNeasy Blood \& Tissue Kit, Qiagen, Venlo, the Netherlands) according to the manufacturer's instructions, as previously described [7]. All samples were subjected to a quantitative PCR (qPCR) targeting a single copy gene encoding a $C$. burnetii-specific hypothetical protein (gene bank number AY502846) using the forward primer 5'-ATAGCGCCAATCGAAATGGT-3', the reverse primer $5^{\prime}$-CTTGAATACCCATCCCGAAGTC$3^{\prime}$, and the NED-labelled probe 5'-CCCAGTAGGGCA GAAGACGTTCCCC-3'. An inhibition control (IC) was constructed using primers for the IS1111a element and a dedicated VIC-labelled probe, as previously published [17]. PCR was performed on a 7500 Fast Real Time PCR system (Applied Biosystems, Waltham, USA), using $400 \mathrm{nmol} / \mathrm{L}$ of primers and $200 \mathrm{nmol} / \mathrm{L}$ of probes in $7 \mu \mathrm{L}$ PerfeCTa Multiplex qPCR Super mix, UNG (2X) with Low Rox dye (Quanta Biosciences, Gaithersburg, USA), $1 \mu \mathrm{L}$ of IC, $5 \mu \mathrm{L}$ of sample and $7 \mu \mathrm{L}$ of water. An initial UDG incubation for $5 \mathrm{~min}$ at $45{ }^{\circ} \mathrm{C}$ and denaturation/ activation for $60 \mathrm{~s}$ at $95{ }^{\circ} \mathrm{C}$ was followed by 50 cycles of denaturation for $10 \mathrm{~s}$ at $95{ }^{\circ} \mathrm{C}$ and annealing for $30 \mathrm{~s}$ at $60{ }^{\circ} \mathrm{C}$. A Ct value of $\geq 40$ was scored as negative and a $\mathrm{Ct}$ value $<40$ scored as positive.

\section{Statistical analysis}

For the serology data, differences between dpi were analyzed using one-way ANOVA. A $p$-value $<0.01(* *)$ was considered statistically significant compared to $0 \mathrm{dpi}$. The maximum $95 \%$ probability of abortion in the ten inoculated goats was calculated as 0.238 .

\section{Results}

\section{Coxiella burnetii infection and excretion}

To study the role of non-pregnant goats in $\mathrm{Q}$ fever herd dynamics, we inoculated nulliparous goats with $C$. burnetii and assessed the $C$. burnetii infection by their IgG and IgM antibody response. All C. burnetii inoculated goats showed an antibody response indicating a successful infection with C. burnetii (Figure 1). The control (sentinel) animals remained seronegative throughout the experiment (Table 2).

PCR analysis of blood samples showed that none of the infected goats developed a bacteremia during the first 7 weeks after inoculation and none of the goats excreted C. burnetii DNA in their feces up to 7 weeks post inoculation. In the air of the animal rooms, C. burnetii DNA was not detected up to 7 weeks post inoculation (Table 1).

After breeding vaginal swabs were negative for C. burnetii DNA at 141 and 155 dpi (14 and 28 days after breeding). Air samples from the two BSL3 boxes were also negative for C. burnetii DNA, so no excretion of C. burnetii was detected (Table 1). During pregnancy air samples, vaginal swabs and feces samples remained negative for C. burnetii DNA (Table 2).

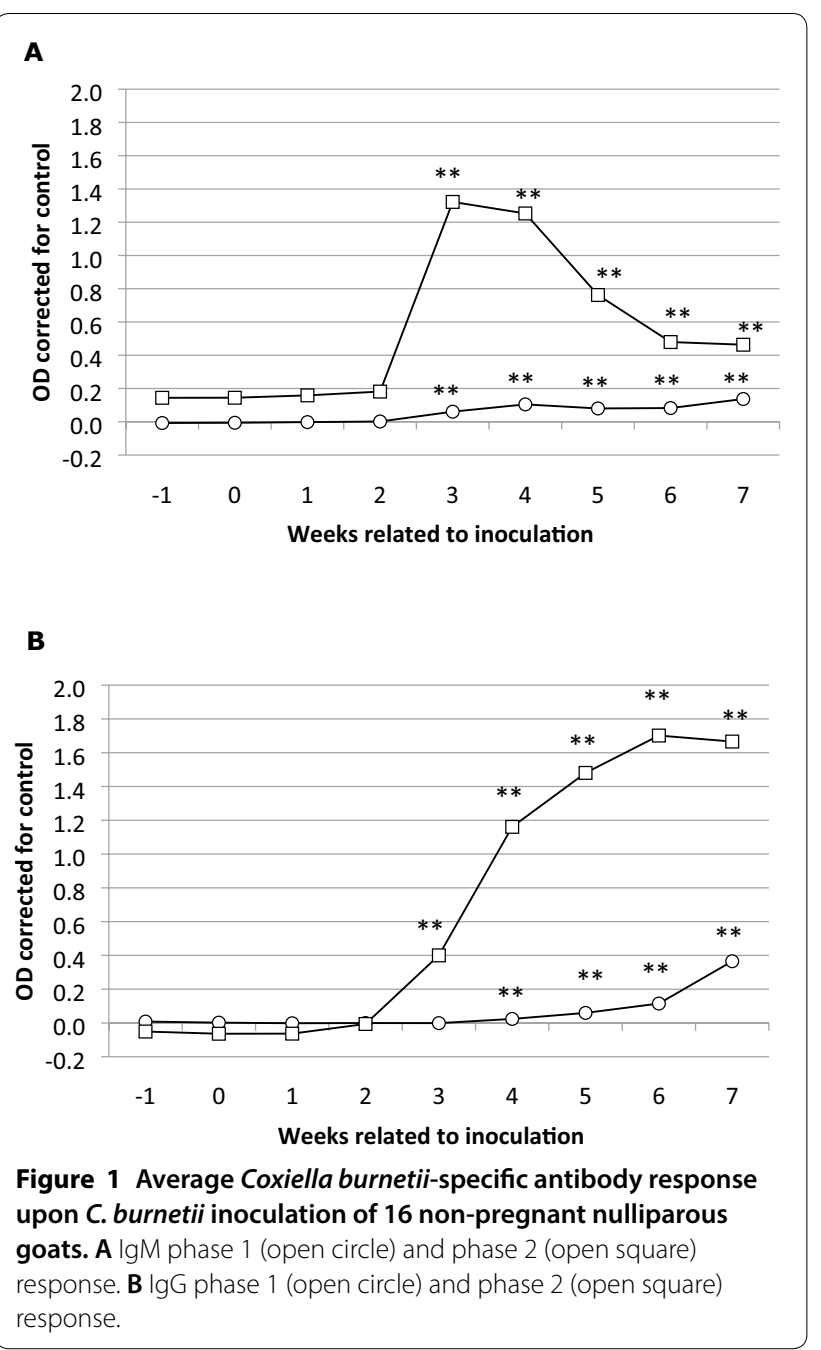




\section{Pregnancy outcome and Coxiella burnetii excretion}

Two infected goats appeared to be non-pregnant at the time of parturition (most likely due to pseudo-pregnancy at the time of echoscopy). One infected goat was still pregnant at termination of the experiment due to nonconception at first mate. The remaining nine infected goats delivered healthy lambs after an average gestation of 152.89 days (95\%CI 151.49-154.29) with on average 2.00 kids (95\%CI 1.49-2.51) and the four control goats kidded after an average gestation of 153.50 days (95\% CI 152.23-154.77) with on average 1.75 kids (95\%CI $0.81-$ 2.69 , Table 3 ). So all pregnant goats kidded full term and no significant differences in gestation length or number of kids was measured between $C$. burnetii inoculated goats and control goats. The placentas of the inoculated does gave no macroscopic indication for inflammation and $C$. burnetii DNA was not detected in the cotyledon or inter-cotyledonary allantochorion. The sentinel goats also showed no macroscopic lesions of the placenta and DNA of C. burnetii was not detected in the placentas. However, in one inoculated goat, C. burnetii DNA was detected in the colostrum (Ct value: 34.05$)$ and the mammary gland (Ct value: 30.26 ). Due to this result, the organs of this doe and her kids were investigated using C. burnetii PCR. None of the other tissues were positive except for the samples from the mammary gland $(\mathrm{Ct}$ value: 28.94), inguinal lymph node (Ct value: 39.14$)$, and colostrum (Ct value: 32.50 ) indicating that $C$. burnetii was present in the mammary tissue of this goat (Table 3 ). So, although $C$. burnetii DNA could not be detected in the placenta after parturition, we were able to detect $C$. burnetii DNA in the colostrum and mammary glands of one out of 10 inoculated goats after parturition. No C. burnetii was detected in the colostrum or mammary gland and lymph nodes of the sentinel animals (Table 3 ).

\section{Discussion}

The goal of this study was to investigate C. burnetii infection and excretion in non-pregnant nulliparous goats up to the outcome of the first pregnancy and colostrum production in order to assess the role of non-pregnant goats in herd $Q$ fever dynamics. Although several inoculation studies on pregnant goats have been published [7, 14-16, 18], no studies are available on non-pregnant goats inoculated under experimental conditions. As the inoculation with $10^{6}$ MID C. burnetii in pregnant goats resulted in pathology, excretion of $C$. burnetii, abortion and seroconversion $[7,16]$, we assessed this procedure as successful and one of the representatives of the field situation, for that reason we used it also to evaluate the goal in this study. Our results indicate that inoculation of non-pregnant goats resulted in an antibody response comparable to the response in inoculated pregnant goats, indicating infection. This C. burnetii-specific antibody response showed a significant increase in phase 2 IgM and IgG after $14 \mathrm{dpi}$. This increase is comparable to the phase 2 IgM and IgG antibody increase in pregnant goats after inoculation with $10^{6}$ MID C. burnetii [16]. The IgM phase 1 antibody response significantly increased after $21 \mathrm{dpi}$, whereas the IgG phase 1 showed a significant increase after $28 \mathrm{dpi}$. The phase $1 \mathrm{IgG}$ response is also comparable with the previous study, although the phase 1 IgM response was slightly lower in that data [16].

After intranasal inoculation and during breeding, no C. burnetii DNA was detected in feces or environmental samples. This indicates that C. burnetii was not excreted after infection and during estrus. Although shedding in non-pregnant goats was reported in several field studies, this was always related to previous kidding with excretion of $C$. burnetii $[9,19,20]$. Experimental studies show that C. burnetii was not excreted before parturition [7], which is in line with the results in this study. Since $C$. burnetii was not detected by PCR in any of the fecal and air samples, the goats could safely be moved from BSL3 facilities to BSL2 facilities, as the risk for spreading C. burnetii in the environment was negligible. This is also important for hobby goat owners and goat farmers as, although goats may be kept in a contaminated environment, non-pregnant goats pose no risk for their environment and as such pose no risk for public health and veterinary health, provided that these animals are not bred.

Breeding and gestation of non-pregnant $C$. burnetii infected goats resulted in a term delivery of a normal number of healthy kids without the excretion of $C$. burnetii DNA or infection of the placenta/afterbirth. In addition, non-infected pregnant sentinel goats, cohoused with the inoculated goats, did not show seroconversion, fecal excretion of $C$. burnetii or abortion due to possible shedding of $C$ burnetii by the infected goats. Given the preference of $C$. burnetii for trophoblast cells, as demonstrated in earlier studies [7, 14], one could have expected that as soon as trophoblast cells arise during the first pregnancy then these cells could have been infected from a source of persistent infection in the doe. The fact that no abortion or infection of placental tissues occurred could have two reasons. Firstly, C. burnetii was not persisting in the goat's tissues. As shown above, non-pregnant goats develop an immune response upon infection and this immune response may well be effective in eliminating the infection. However, this does not seem to be the case for one out of 10 goats, in which C. burnetii DNA was detected in the mammary gland, associated lymph nodes and colostrum. A second explanation could be that in persistently infected goats, circulation of bacteria does not occur or bacteria are eliminated when entering the 


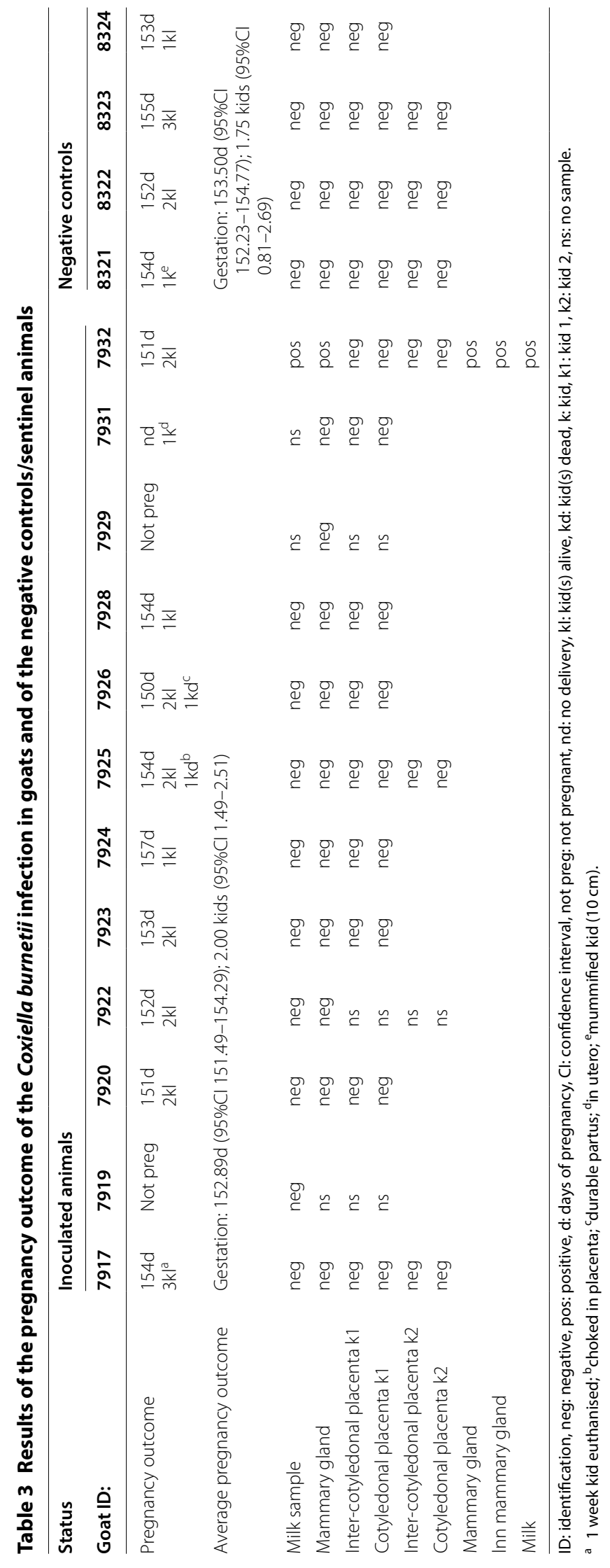


circulation and so trophoblast cells are not infected via this route. This is supported by the data that revealed no indications for circulating C. burnetii immediately after infection, although the bacteremia might remain under the detection limit of the sampling and test. As the trophoblasts were not infected, C. burnetii is not excreted upon delivery and therefore the risk non-pregnant goats pose in a herd can be assessed as low.

Although the number of goats in this study is relatively small, which hamper the negative predictive value, we anticipate that infection of non-pregnant goats does not result in substantial excretion of C. burnetii upon breeding. In earlier experiments with pregnant goats, the success rate of inoculation and subsequent $C$. burnetii excretion upon delivery was $100 \%[7,14,15]$. We therefore assumed that breeding is the ultimate test for the infection status of goats. This, however, appeared not to be true. Even if goats do not excrete C. burnetii via the placenta and birth fluids, goats can still be infected and excrete C. burnetii via the colostrum.

In one of the ten inoculated goats, C. burnetii DNA was detected in the mammary gland, associated lymph nodes and colostrum. This is remarkable as C. burnetii was not excreted with the placenta or kids upon delivery. The result is, however, in line with earlier studies, which show excretion of $C$. burnetii DNA in the milk and persistence of DNA of the bacterium in the mammary gland [13]. These earlier studies, however, provided no clues about the origin of the C. burnetii persisting in the mammary gland: did these enter during an infected pregnancy or were they already present before the pregnancy? Our results indicate that the latter is possible. The only origin of the C. burnetii in our study is the inoculation before breeding, so in non-pregnant goats. The preference of C. burnetii for mammary tissues was already demonstrated in an in vitro comparison study in which the susceptibility of different epithelial cells for C. burnetii was assessed [21]. The persistence of DNA and presumably infectious C. burnetii in the mammary gland, and especially the excretion in the colostrum, potentially results in infection of the suckling kids and contamination of the environment. From this contaminated environment, highly susceptible pregnant goats can be infected for example via automatic milking systems. In this way nonpregnant goats that are infected with $C$. burnetii before breeding, could play a role in the dynamics of $Q$ fever in a goat herd although the exact attribution of pre-bred infected goats cannot be derived from this study. This risk can be further reduced by vaccinating the kids as early as possible, which Muleme et al. have already suggested as an approach for eradicating $Q$ fever from an infected herd [22].

\section{Abbreviations}

MID: mouse-infective dose; aBSL: animal biosafety level; dpi: days postinoculation; h: hour; IC: inhibition control; OD: optical density; ID: identification; neg: negative; pos: positive; i.m.: intramuscular; D: day in study; d: days of pregnancy; Cl: confidence interval; nd: no delivery; not preg: not pregnant; $\mathrm{kl}$ : kid(s) alive; kd: kid(s) dead; k: kid; k1: kid 1; k2: kid 2; ns: no sample.

\section{Acknowledgements}

The authors thank Frederique Bouvier and Francis Barillet from INRAE (France) for their cooperation in providing the goats. Colleagues from the Department of Animal Husbandry are thanked for their dedicated care of the goats and sampling during the experiment. Dave Thomas is thanked for editing the manuscript.

\section{Authors' contributions}

Conceived and designed the experiments: HIJR, JP, LVK. Performed the experiments: HIJR, AD, JP, LVK. Analyzed the data: HIJR, AD, JP, LVK. Wrote the paper: HIJR, Ad, AK, JP, LVK. All authors read and approved the final manuscript.

\section{Funding}

This study was financially supported by the Dutch Ministry of Agriculture, Nature and Food Quality under the Regulatory research tasks, research part program, KB-12-005.01-003.

\section{Availability of data and materials}

The datasets during and/or analysed during the current study are available from the corresponding author on reasonable request.

\section{Competing interests}

The authors declare that they have no competing interests.

\section{Author details}

${ }^{1}$ Department of Bacteriology and Epidemiology, Wageningen Bioveterinary Research, Lelystad, The Netherlands. ${ }^{2}$ Department of Large Animal Health, Faculty of Veterinary Medicine, Utrecht University, Utrecht, The Netherlands. ${ }^{3}$ Department of Virology, Wageningen Bioveterinary Research, Lelystad, The Netherlands. ${ }^{4}$ Department of Infection Biology, Wageningen Bioveterinary Research, Lelystad, The Netherlands. ${ }^{5}$ Present Address: Ministry of Agriculture, Nature and Food Quality, The Hague, The Netherlands.

Received: 8 March 2020 Accepted: 8 May 2020

Published online: 29 May 2020

\section{References}

1. Alvarez-Alonso R, Basterretxea M, Barandika JF, Hurtado A, Idiazabal J, Jado I, Beraza X, Montes M, Liendo P, Garcia-Perez AL (2018) A Q fever outbreak with a high rate of abortions at a dairy goat farm: Coxiella burnetii shedding, environmental contamination, and viability. Appl Environ Microbiol 84:e01650-18

2. Roest HI, Tilburg JJ, van der Hoek W, Vellema P, van Zijderveld FG, Klaassen CH, Raoult D (2011) The Q fever epidemic in The Netherlands: history, onset, response and reflection. Epidemiol Infect 139:1-12

3. Porten K, Rissland J, Tigges A, Broll S, Hopp W, Lunemann M, van Treeck U, Kimmig P, Brockmann SO, Wagner-Wiening C, Hellenbrand W, Buchholz U (2006) A super-spreading ewe infects hundreds with Q fever at a farmers' market in Germany. BMC Infect Dis 6:147

4. Kampschreur LM, Hagenaars JC, Wielders CC, Elsman P, Lestrade PJ, Koning OH, Oosterheert JJ, Renders NH, Wever PC (2013) Screening for Coxiella burnetii seroprevalence in chronic Q fever high-risk groups reveals the magnitude of the Dutch $\mathrm{Q}$ fever outbreak. Epidemiol Infect 141:847-851

5. van Roeden SE, Wever PC, Kampschreur LM, Gruteke P, van der Hoek W, Hoepelman AIM, Bleeker-Rovers CP, Oosterheert JJ (2018) Chronic Q fever-related complications and mortality: data from a nationwide cohor. Clin Microbiol Infect 25:1390-1398

6. Georgiev M, Afonso A, Neubauer H, Needham H, Thiery R, Rodolakis A, Roest H, Stark K, Stegeman J, Vellema P, van der Hoek W, More S (2013) Q fever in humans and farm animals in four European countries, 1982 to 2010. Euro Surveill 18:20407 
7. Roest HJ, van Gelderen B, Dinkla A, Frangoulidis D, van Zijderveld FG, Rebel J, van Keulen L (2012) Q fever in pregnant goats: pathogenesis and excretion of Coxiella burnetii. PLoS One 7:e48949

8. Berri M, Rousset E, Champion JL, Russo P, Rodolakis A (2007) Goats may experience reproductive failures and shed Coxiella burnetii at two successive parturitions after a $\mathrm{Q}$ fever infection. Res Vet Sci 83:47-52

9. Berri M, Rousset E, Hechard C, Champion JL, Dufour P, Russo P, Rodolakis A (2005) Progression of $Q$ fever and Coxiella burnetii shedding in milk after an outbreak of enzootic abortion in a goat herd. Vet Rec 156:548-549

10. Berri M, Souriau A, Crosby M, Rodolakis A (2002) Shedding of Coxiella burnetii in ewes in two pregnancies following an episode of Coxiella abortion in a sheep flock. Vet Microbiol 85:55-60

11. de Cremoux R, Rousset E, Touratier A, Audusseau G, Nicollet P, Ribaud D, David V, Le Pape M (2012) Coxiella burnetii vaginal shedding and antibody responses in dairy goat herds in a context of clinical $Q$ fever outbreaks. FEMS Immunol Med Microbiol 64:120-122

12. Alsaleh A, Pellerin JL, Rodolakis A, Larrat M, Cochonneau D, Bruyas JF, Fieni $F$ (2011) Detection of Coxiella burnetii, the agent of $Q$ fever, in oviducts and uterine flushing media and in genital tract tissues of the non-pregnant goat. Comp Immunol Microbiol Infect Dis 34:355-360

13. Van den Brom R, van Engelen E, Vos J, Luttikholt SJM, Moll L, Roest HIJ, van der Heijden HMJF, Vellema P (2013) Detection of Coxiella burnetii in the bulk tank milk from a farm with vaccinated goats, by using a specific PCR technique. Small Rumin Res 110:150-154

14. Arricau Bouvery N, Souriau A, Lechopier P, Rodolakis A (2003) Experimental Coxiella burnetii infection in pregnant goats: excretion routes. Vet Res 34:423-433

15. Sanchez J, Souriau A, Buendia AJ, Arricau-Bouvery N, Martinez CM, Salinas J, Rodolakis A, Navarro JA (2006) Experimental Coxiella burnetii infection in pregnant goats: a histopathological and immunohistochemical study. J Comp Pathol 135:108-115

16. Roest HI, Post J, van Gelderen B, van Zijderveld FG, Rebel JM (2013) Q fever in pregnant goats: humoral and cellular immune responses. Vet Res 44:67
17. Roest HI, Ruuls RC, Tilburg JJ, Nabuurs-Franssen MH, Klaassen CH, Vellema $P$, van den Brom R, Dercksen D, Wouda W, Spierenburg MA, van der Spek AN, Buijs R, de Boer AG, Willemsen PT, van Zijderveld FG (2011) Molecular epidemiology of Coxiella burnetii from ruminants in Q fever outbreak, the Netherlands. Emerg Infect Dis 17:668-675

18. Arricau-Bouvery N, Souriau A, Bodier C, Dufour P, Rousset E, Rodolakis A (2005) Effect of vaccination with phase I and phase II Coxiella burnetii vaccines in pregnant goats. Vaccine 23:4392-4402

19. Rousset E, Berri M, Durand B, Dufour P, Prigent M, Delcroix T, Touratier A, Rodolakis A (2009) Coxiella burnetii shedding routes and antibody response after outbreaks of $\mathrm{Q}$ fever-induced abortion in dairy goat herds. Appl Environ Microbiol 75:428-433

20. Rodolakis A, Berri M, Hechard C, Caudron C, Souriau A, Bodier CC, Blanchard B, Camuset P, Devillechaise P, Natorp JC, Vadet JP, Arricau-Bouvery $N$ (2007) Comparison of Coxiella burnetii shedding in milk of dairy bovine, caprine, and ovine herds. J Dairy Sci 90:5352-5360

21. Sobotta K, Bonkowski K, Liebler-Tenorio E, Germon P, Rainard P, Hambruch N, Pfarrer C, Jacobsen ID, Menge C (2017) Permissiveness of bovine epithelial cells from lung, intestine, placenta and udder for infection with Coxiella burnetii. Vet Res 48:23

22. Muleme M, Campbell A, Stenos J, Devlin JM, Vincent G, Cameron A, Graves S, Wilks CR, Firestone S (2017) A longitudinal study of serological responses to Coxiella burnetii and shedding at kidding among intensivelymanaged goats supports early use of vaccines. Vet Res 48:50

\section{Publisher's Note}

Springer Nature remains neutral with regard to jurisdictional claims in published maps and institutional affiliations.
Ready to submit your research? Choose BMC and benefit from:

- fast, convenient online submission

- thorough peer review by experienced researchers in your field

- rapid publication on acceptance

- support for research data, including large and complex data types

- gold Open Access which fosters wider collaboration and increased citations

- maximum visibility for your research: over $100 \mathrm{M}$ website views per year

At BMC, research is always in progress.

Learn more biomedcentral.com/submissions 